\title{
Ramor 500 Çeliğinde Isıl İşılemin Mikroyapı, Mikrosertlik ve Abrasiv Aşınma Direncine Etkisinin Taguchi Metoduyla Değerlendirilmesi
}

\author{
Ali Kaya GÜR ${ }^{1}$, Semih TAŞKAYA ${ }^{1 *}$, Çetin ÖZAY ${ }^{2}$ \\ ${ }^{I}$ Fırat Üniversitesi, Teknoloji Fakültesi, Metalurji ve Malzeme Mühendisliği Bölümü, 23119, Elazı̆̆, Türkiye \\ ${ }^{2}$ Frrat Üniversitesi, Teknoloji Fakültesi, Makina Mühendisliği Bölümü, 23119, Elazığ, Türkiye \\ (ORCID: 0000-0001-6077-1892) (ORCID: 0000-0003-1524-4537) (ORCID: 0000-0001-9958-519X)
}

\begin{abstract}
Öz
Ramor 500 zırh çeliği; 2-30 mm kalınlıklara sahip, 505-590 HV sertliklerde bulunan yüksek mukavemetli bir balistik koruma çeliği olarak sınıflandırılır. Aşınma, kayma yüzeyleri arasındaki mekanik etkinin etkisiyle yüzeyler üzerinde malzemenin deformasyonuna ve kaybına neden olan bir etkileşim işlemidir. Bu çalışmada, konstrüksiyon imalat sanayisinde kullanılan Ramor 500 çeliğinin 1 sıl işlem sonrası mikroyapı, mikrosertlik ve abrasiv aşınma direncine etkisinin taguchi metoduyla değerlendirilmesi ve etkileri incelenmiştir. Bu amaçla Ramor 500 çeliği $900^{\circ} \mathrm{C}$ sıcaklıkta tavlanmış ve 3 faklı ortamda soğutulmuştur. İnceleme sonucunda mikroyapı ve mikrosertlik incelenmiştir. Ayrıca 1sıl işlemsiz numunelerle kıyaslamak maksadıyla abrasiv aşınma testine tabi tutulmuştur. Elde edilen veriler Taguchi metoduyla değerlendirilip Varyans analizleriyle seviye ve parametrelerin aşınmaya olan etkileri incelenmiştir. Yapılan $1 s ı l$ işlemler sonrasında sertlik değerlerinde esas metalin altında kalınmıştır. Seçilen bütün parametrelerin aşınmaya etkisi olmuştur. Kütle kaybının kontrol faktörleri üzerindeki etkisi countour plot renk dağılımı metoduyla gözlemlenmiştir.
\end{abstract}

Anahtar kelimeler: Ramor 500, Isıl işlem, Taguchi.

\section{The Evaluation of the Effect of Heat Treatment on Microstructure, Microhardness and Abrasive Wear Resistance with Taguchi Method of Ramor 500 Steel}

\begin{abstract}
The Ramor 500 armor steel is classified as a high strength ballistic protection steel with 2-30 mm thicknesses and 505-590 HV hardnesses. Wear is an interaction process that causes deformation and loss of the material on surfaces due to the mechanical effect between the sliding surfaces. In this study, the effect of Ramor 500 on the microstructure, microhardness and abrasive wear resistance of heat treatment after Ramor 500 steel used in the construction manufacturing industry was investigated by taguchi method. For this purpose, Ramor 500 steel was annealed at $900^{\circ} \mathrm{C}$ and cooled in 3 different environments. The microstructure and microhardness were investigated. In addition, it has been subjected to abrasive abrasion test to compare with non-heat-treated samples. The data obtained were evaluated by Taguchi method and the effects of level and parameters on wear were examined with variance analysis. After the heat treatment, the hardness values were below the base metal. All selected parameters had an effect on wear. The effect of mass loss on control factors was observed by countour plot color distribution method.
\end{abstract}

Keywords: Ramor 500, Heat treatment, Taguchi.

\section{Giriş}

Ramor 500 zırh çelikleri yüksek hız darbelerine karşı üretilir. Ayrıca araç aydınlatması için otomotiv endüstrisinde kullanılır. Örneğin, beton bir karıştırıcıda yerleşik donanım, yapısal çelikten daha ince

\footnotetext{
*Sorumlu yazar: muh.semihtaskaya@gmail.com

Geliş Tarihi: 25.02.2019, Kabul Tarihi: 01.07.2019
} 
plaka ile Ramor 500 çelik kullanılarak üretilebilir. Böylece daha dinamik verimlilik ve yakıt tasarrufu sağlar [1]. Koruyucu malzeme seçimi ateşli silahlardan çıkan merminin, penetratörün ya da ateşli parçacığın türü, geometrisi ve penetrasyon kinetiğine göre yapılır. Belirtilen malzemeler arasında homojen olarak haddelenmiş zırh çelikleri (RHA, Rolled Homogeneous Armor) askeri platformlarda çok çeşitli, personel ve mühimmat taşıyan araçlarda koruyucu malzeme olarak kullanılmalıdır [2]. Zırh çeliği, günümüzde özellikle askeri alanda kullanılan tank ve benzeri savunma ve saldırı amaçlı olarak en yaygın kullanılan zırh malzemesidir. Çelik kullanılmasının başlıca nedeni çeliklerde yüksek dayanım özellikleri görülmesi, yeterli tokluk, yüksek kaynak kabiliyeti gibi malzeme özellikleri ve diğer zırh malzemelerine göre daha düşük olan üretim maliyetleridir. Kaynak endüstride çok yaygın olarak kullanılan bir imalat yönteminin yanı sıra, tamir amaçlı bir yöntem olarak da çok yaygın olarak kullanılmaktadır. Zırh uygulamalarının yapıldığı ağır ve hafif taşıtların değişik ve çetin arazilerdeki hareketlerinden, mermi mukavemetlerine karşı kaynak bölgelerinin yorulma direncinin yüksek olması gereklidir [3-7]. Taguchi deney tasarım yöntemi, deneysel çalışmaların daha kısa ve kolay yapılmasını sağlayan deney sayısını minimize etmeye çalışan bir deney tasarım yöntemidir. Taguchi dizayn metodu, Dr. Genichi Taguchi tarafından geliştirilen bir deneysel dizayn metodudur. Bu metot 1980 yıllarından sonra Avrupa ve Amerika endüstrisinde yaygın olarak kullanılmaya başlamıştır. Bu yöntem sayesinde uzun ve pahalı deneylerin optimizasyonunu tam faktöryel yöntemine göre daha az deney ile yapılabilmektedir. Deneysel çalışmalardaki parametrelerin etkinliğini belirleyebilen ve bunun yanı sıra deney süresini düşüren, maliyeti azaltan bir yöntemdir. Deneysel çalışma planı hazırlanırken, deneylerde kullanılacak parametre ve bunlara ait seviyeleri belirir. Daha sonra, bunların serbestlik derecelerine uygun ortagonal dizinlerin seçilmesi ile sistem oluşturulur. Deneysel çalışmaların yorumlanmasında $\mathrm{S} / \mathrm{N}$ (sinyal/gürültü) oranı denilen performans karakteristikliğine dönüştürülmektedir. En çok kullanılan performans karakteristiklikleri en küçük en iyi (the smallest, the best), en büyük en iyi (The biggest, the best) ve nominal en iyi (Nominal best) karakteristiklikleridir [8-13]. Gajjal vd., çalışmalarında farklı tip ve miktarda dolgu maddesi içeren PEEK kompozitlerin tribolojik davranışlarını incelemişlerdir. PEEK kompozit malzemelerin kayma hızı, basınç ve zaman gibi çalışma parametrelerinin tribolojik performansı üzerine etkileri incelenmiştir. Taguchi'nin tekniğine dayanan deney planı kullanılarak, bir diske bağlı pin üzerinde aşınma testleri yapılmıştır. PEEK'nin CF, PTFE ve grafit ile güçlendirilmiş olduğu, tribolojik performansı etkili bir şekilde artırabileceği görülmüştür [14]. Paturkar vd., çalışmasında hint keneviri / epoksi ve hint keneviri/ cam / epoksi kompozitlerin davranışlarını mekanik aşınma koşulu altında incelemişlerdir. Sonuçlar, Taguchi tekniği kullanılarak ayrıca analiz edildi. Kompozit plakaların aşınma performansına etkisi, farklı kayma hızları $(1 \mathrm{~m} / \mathrm{s}, 2 \mathrm{~m} / \mathrm{s}$ ve $3 \mathrm{~m} / \mathrm{s})$, uygulanan yükler ( $10 \mathrm{~N}, 20 \mathrm{~N}$ ve $30 \mathrm{~N})$ ve kayma mesafeleri $(1000 \mathrm{~m}, 1500 \mathrm{~m}$ ve $2000 \mathrm{~m})$ için araştırıldı. Deneysel sonuçlar, jüt epoksi cam elyaf ile melezleştirilmesinin aşınmaya karşı daha iyi direnç gösterdiğini göstermiştir. Ayrıca uygulanan yükün kompozitlerin tribolojik performansı üzerinde daha etkili parametreler olduğu görülmüştür [15]. Hofinger vd., bu çalışmada farklı 1sıl işlemlerin mikroyapı gelişimi ve ikincil sertlik üzerindeki etkisini incelemişlerdir. Mikro yapıyı görselleştirmek için farklı metalografik hazırlama yöntemleri test edilmiştir. Karbürler, spot paternli elektron geri saçılma kırınımı kullanılarak karakterize edilmiştir. Östenitlemeden önce homojenleştirme işleminin, çözünmüş karbür miktarını arttıramadığı ve dolayısıyla ikincil sertlik üzerinde bir etkisinin olmadığı bulunmuştur [16]. Atapek yaptığı araştırmada, zırh çeliklerinin sahip olduğu mekanik ve balistik performansa eşdeğer ve yüksek performanslı malzeme üretimi için yeni bir alaşım tasarımı ile farklı ısıl işlem uygulamaları seçmiştir. Isıl işlem koşullarına bağlı olarak geliştirilen zırh çeliğinin sertlik, mukavemet, tokluk, aşınma gibi mekanik özelliklerinin ve korozyon direncinin dişında, V50 balistik limiti ve yüksek çarpma hızlarındaki performansını araştırmıştır. Araştırmaları sonucunda zırh çeliklerinin alaşım tasarımı üzerine daha farklı çalışmalar yapılması gerektiği kanısına varmıştır. Hızlı su verme ile çeliklerde martenzitik/beynitik dönüşüm gözlemlemiş olup, martenzit/bennit başlangıç sıcaklığının oda sıcaklığının çok üzerinde bir değer olduğunu görmüştür. Aşınma davranışlarını incelediğinde yüksek sertlikteki zırh çeliklerinin düşük sertlikteki zırh çeliklerine göre daha düşük aşınma dayanımı gösterdiğini gözlemlemiştir. Yapılan balistik testler sonucunda geliştirilen zırh çeliğinin daha yüksek V50 balistik limitlere sahip olduğunu gözlemlemiştir [17]. Atapek çalışmasında, bor katkılı yeni tür bir alaşımlandırma dizaynı geliştirerek, uygulanan çeşitli isıl işlemlerle zırhın performansında etkili olan optimum mekanik özelliklerin balistik karakteristiğine uygun bir aralık içinde elde edilmesini araştırmıştır. Yapılan bu çalışma sonucunda, bor katkılı kompozisyon doğrultusunda sadece değişen 1sıl işlem koşulları altında geniş bir sertlik ve dolayısı ile mukavemet aralığında zırh 
çeliği üretimi sağlamıştır [18]. Karakoç vd., çalışmalarında toz metalurjisi yöntemi ile hazırlanan SiC, $\mathrm{B} 4 \mathrm{C}$ ve $\mathrm{Al} 2 \mathrm{O} 3$ içeren ve parçacık içermeyen $\mathrm{Al}$ sandviç köpüklerin (ASK) balistik performansları araştırmışlardır. Üretilen sandviç köpükler 50x50x7 mm2 boyutlara sahip olan Ramor 500 zırh çeliği silikon esaslı reçine ile yapıştırılarak balistik test için zırh numuneleri hazırlamışlardır. Yapılan çalışmada sonucunda, sandviç köpüklerin önde olduğu tasarımlarda zırh çeliğinden kopan parçacık çapının daha az olduğu tespit edilmiştir [19].

$\mathrm{Bu}$ çalışmada, Ramor 500 çelik numunelere 1sıl işlem uygulanarak mikrosertlik, mikroyapı değişimleri incelenmiş ve abrasiv aşınma sistemiyle $\mathrm{SiC}$ partiküllü aşındırıcıda meydana gelen kütle kaybı aşınma davranışı Taguchi yöntemiyle incelenmiştir.

\section{Materyal ve Metot}

\subsection{Isıl İşlem ve Taguchi Dizaynı}

$\mathrm{Bu}$ çalışmada endüstriden temin edilen mikroalaşımlı Ramor 500 kullanılmıştır. Bu çeliğe östenitleme sıcaklığı üzerinde 1 ssl işlem uygulanmıştır. $\mathrm{Bu} 1$ ssıl işlem sonucunda $\mathrm{Ac} 3+\left(30^{\circ}-50^{\circ} \mathrm{C}\right)$ sicaklığ ki bekletme işlemiyle, çeliğin yapısının tamamen östenit yapılması ya da sementitin parçalanması sonucu karbonun yapı içerisinde tamamen çözünmesi amaçlanmıştır. Bu süre genellikle 1 inç $(25,4 \mathrm{~mm})$ kalınlık için 1 saat olarak kabul edilmektedir. Çelikteki C miktarına bağlı olarak tavlama sıcaklığındaki değişim C oranı $0.29-0.38$ olan çelikler için $840-900^{\circ} \mathrm{C}$ olarak belirlenmiştir [20].

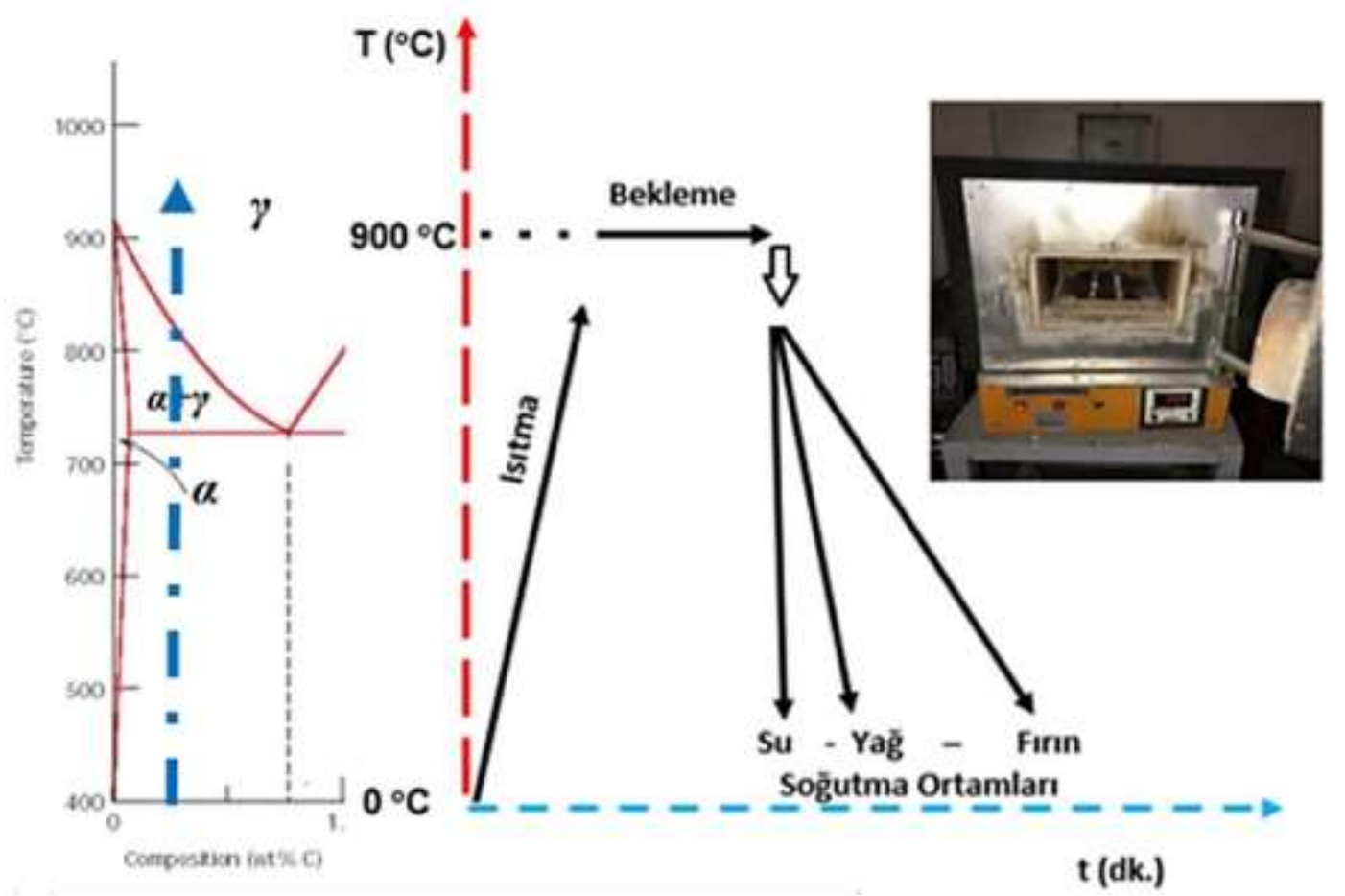

Şekil 1. Isıl işlem grafiği ve tav firını

$\mathrm{Bu}$ amaçla seçilen numuneler Şekil 1'de ki isıl işlem tav fırınında $900{ }^{\circ} \mathrm{C}$ 'ye kadar 1sıtılmış, bu sıcaklıkta $30 \mathrm{dk}$. beklenmiş ve numunelerin biri suda, diğeri yağda ve sonuncusunda firın içinde soğutulmuştur. Deneyde kullanılan Ramor 500 çeliğinin kimyasal kompozisyonu fiziksel ve mekanik özellikleri toplu olarak Tablo 1'de verilmiştir. 
Tablo 1. Ramor 500 çeliğinin kimyasal fiziksel ve mekanik özellikleri [3, 22-23]

\begin{tabular}{|c|c|c|c|c|c|c|c|c|c|c|}
\hline \multirow{10}{*}{ 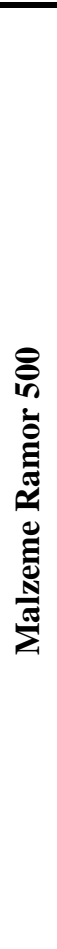 } & \multicolumn{10}{|c|}{ Kimyasal Kompozisyon (\%) } \\
\hline & $\mathbf{C}$ & $\mathbf{S i}$ & Mn & $\overline{\mathbf{P}}$ & $\overline{\mathbf{S}}$ & $\mathrm{Cr}$ & $\mathbf{N i}$ & Mo & $\mathbf{B}$ & $\mathbf{F e}$ \\
\hline & 0.32 & 0.70 & 1.50 & 0.015 & 0.005 & 1.00 & 2.00 & 0.70 & 0.005 & Balans \\
\hline & \multicolumn{10}{|c|}{ Fiziksel Özellikler } \\
\hline & \multicolumn{3}{|c|}{$\begin{array}{l}\text { Termal Genleşme } \\
\text { Katsayısı }\left(\alpha 1^{-6}\right)\end{array}$} & \multicolumn{3}{|c|}{$\begin{array}{c}\text { Termal İletkenlik } \\
\left(20^{\circ} \mathrm{C}\right),\left(\lambda, \mathrm{W} / \mathrm{m} .{ }^{\circ} \mathrm{K}\right)\end{array}$} & $\begin{array}{r}\text { El } \\
\text { D } \\
(20\end{array}$ & $\begin{array}{l}\text { rik } \\
\text { ( }(\Omega)\end{array}$ & $\begin{array}{r}\text { Elastisite } \\
\left(20^{\circ}\right. \\
(\mathrm{E}, \mathrm{kN} /\end{array}$ & odülü \\
\hline & \multicolumn{3}{|c|}{12} & \multicolumn{3}{|c|}{58} & \multicolumn{2}{|c|}{$140-250$} & \multicolumn{2}{|c|}{210} \\
\hline & \multicolumn{10}{|c|}{ Mekanik Özellikler } \\
\hline & $\overline{A k \mathbf{A}}$ & Daya & Imı & Çek & me Day & nımı & & & Mikrosertlik & Tokluk \\
\hline & & $\%(\mathrm{Mr}$ & & & (MPa) & & & & (Vickers HV) & $\mathbf{V} \mathbf{J}$ \\
\hline & & 1450 & & & 1700 & & & & $505-590$ & 20 \\
\hline
\end{tabular}

\subsection{Taguchi Dizaynı}

Bu çalışmada; numuneler, aşınma mesafesi, aşındırıcı tane boyutu ve uygulanan yük olmak üzere dört ayrı kontrol faktörü kullanılmıştır. Bu dört faktör için ilk ikisi 4 diğer ikisinin 2'li seviyeleri seçilmiştir. Çalışmamızda kullandığımız parametreler ve her parametrenin kendi seviyeleri Tablo 2'de verilmiştir. Parametre ve seviyeleri eşit olmadığından Tablo 2'deki karışık seviyeli dizin olan L16 $(4 * 2,2 * 2)$ Taguchi dizini seçilerek Taguchi tasarımı oluşturulmuştur.

Tablo 2. Numunelerin Kontrol faktörleri ve seviyeleri

\begin{tabular}{clcccc}
\hline Sembol & Test Parameteresi & Seviye I & Seviye II & Seviye III & Seviye IV \\
\hline A & Numuneler & Fırın & Yă̆ & Su & Isıl İşlemsiz \\
\hline B & Aşınma Mesafesi (m) & 10 & 20 & 30 & 40 \\
\hline C & Uygulanan Yük (N) & 6 & 16 & - & - \\
\hline D & Aşındırıcı Tane Boyutu(mesh) & 120 & 180 & - & - \\
\hline
\end{tabular}

Abrasiv aşındırma numuneleri; Taguchi dizaynlarında verilen parametrelerin dizaynına göre seviyeleri; aşındırıcı olarak 120 ve 180 mesh'lik zımpara kâğıdı ile $6 \mathrm{~N}$ ve $16 \mathrm{~N}$ 'luk iki farklı yük uygulanarak gerçekleştirilmiştir. Her yük altında 10, 20, 30 ve 40 m'lik mesafelerde ayrı ayrı aşınma deneyi yapılmıştır. Abrasiv aşınma deneyleri Şekil 2'de şematik resmi verilen aparatın torna tezgahına bağlanmasıyla gerçekleştirilir. Abrasiv aşınma deneylerinde aşınma hızı 16 devir/dakika olarak seçilmiştir. Aşınma hızının düşük seçilmesi; aşınma sırasında oluşan aşınma direnci sebebiyle sıçramaları en az seviyeye çekmektir [12-13]. Aşınan numunenin zımpara yüzeyinde elde ettiği aşınma mesafesi torna tezgâhındaki vida adımı ve devir/dakika hesabıyla tespit edilmiştir. 


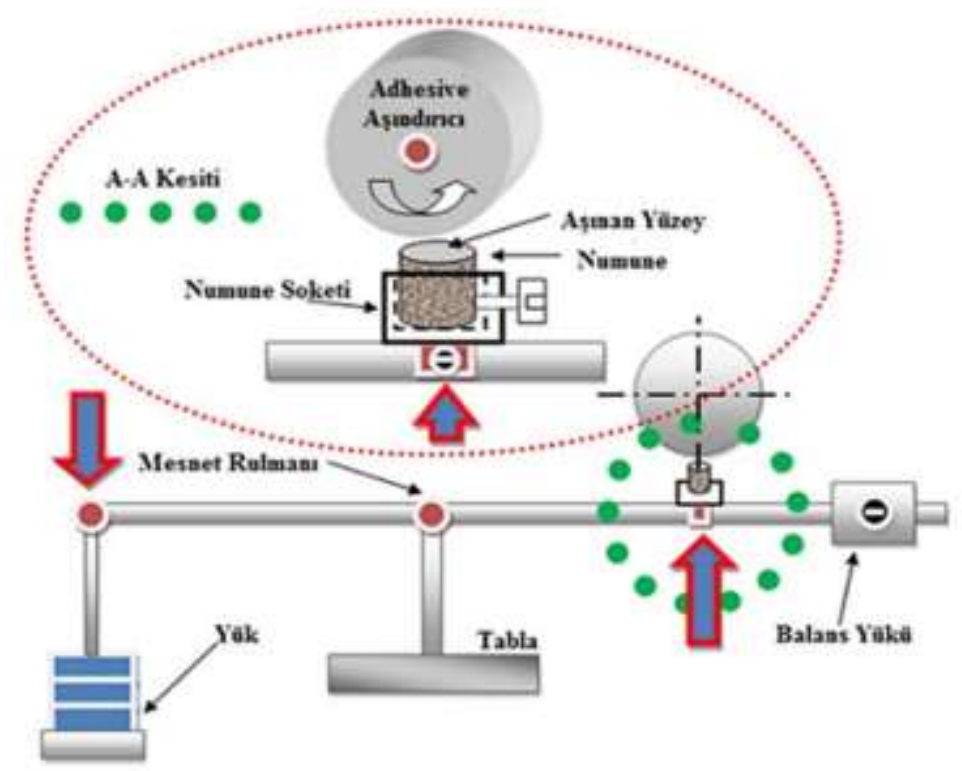

Şekil 2. Abrasiv aşınma mekanizması [11]

Ramor 500 mikroalaşımlı çeliğin Taguchi dizaynı, Minitab 14 paket programından

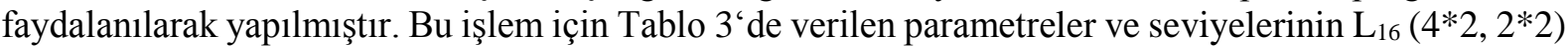
Taguchi dizini oluşturulmuştur. $\mathrm{Bu}$ parametreler dört adet numune (firında soğutulmuş, yağda soğutulmuş, suda soğutulmuş ve isıl işlemsiz), dört adet aşınma mesafesi (m), iki adet yük(N) ve iki adet aşındırıcı (tane boyutu-grid) seviyeye sahip parametrelerdir.

Tablo 3. Deney numuneleri ve aşınma parametreleri

\begin{tabular}{ccccc}
\hline \multirow{2}{*}{$\begin{array}{c}\text { Sıra } \\
\text { No }\end{array}$} & Numune & $\begin{array}{c}\text { Aşınma } \\
\text { Mesafesi } \\
(\mathbf{m})\end{array}$ & $\begin{array}{c}\text { Yük } \\
(\mathbf{N})\end{array}$ & $\begin{array}{c}\text { Aşındırıci } \\
\text { (grid) }\end{array}$ \\
\hline 1 & 1 & 10 & 6 & 120 \\
\hline 2 & 1 & 20 & 6 & 120 \\
\hline 3 & 1 & 30 & 16 & 180 \\
\hline 4 & 1 & 40 & 16 & 180 \\
\hline 5 & 2 & 10 & 6 & 180 \\
\hline 6 & 2 & 20 & 6 & 180 \\
\hline 7 & 2 & 30 & 16 & 120 \\
\hline 8 & 2 & 40 & 16 & 120 \\
\hline 9 & 3 & 10 & 16 & 120 \\
\hline 10 & 3 & 20 & 16 & 120 \\
\hline 11 & 3 & 30 & 6 & 180 \\
\hline 12 & 3 & 40 & 6 & 180 \\
\hline 13 & 4 & 10 & 16 & 180 \\
\hline 14 & 4 & 20 & 16 & 180 \\
\hline 15 & 4 & 30 & 6 & 120 \\
\hline 16 & 4 & 40 & 6 & 120 \\
\hline
\end{tabular}

Kaplama tabakalarının abrasiv aşınma direnci, bu orthogonal dizin kullanılarak en düşük en iyi kontrol özelliğiyle deneysel ve teorik olarak incelenmiştir. Taguchi metoduyla elde edilen veriler, deney sonuçlarına göre grafiksel analizleriyle değerlendirilmiştir. 


\section{Bulgular ve Tartışma}

\subsection{Mikroyapının İncelenmesi}

Isıl işlem sonrası soğutma ortamlarının farklılığı soğutma hızlarını etkilediğinden, tavlama sıcaklığından yani östenit yapıdan dönüşümler soğuma zamanına bağlı olarak homojen tamamlanamamaktadır. $\mathrm{Bu}$ durumda mikroyapılardaki farklılığı oluşturmaktadır. Şekil 3'de de görüldüğü gibi en yavaş soğuma hızı fırın ortamında gerçekleştiğinden taneler diğerlerine nazaran daha iri görünümlüdür. En küçük tane yapısı ise 1 sıl işleme tabi tutulmamış numunede mevcuttur.
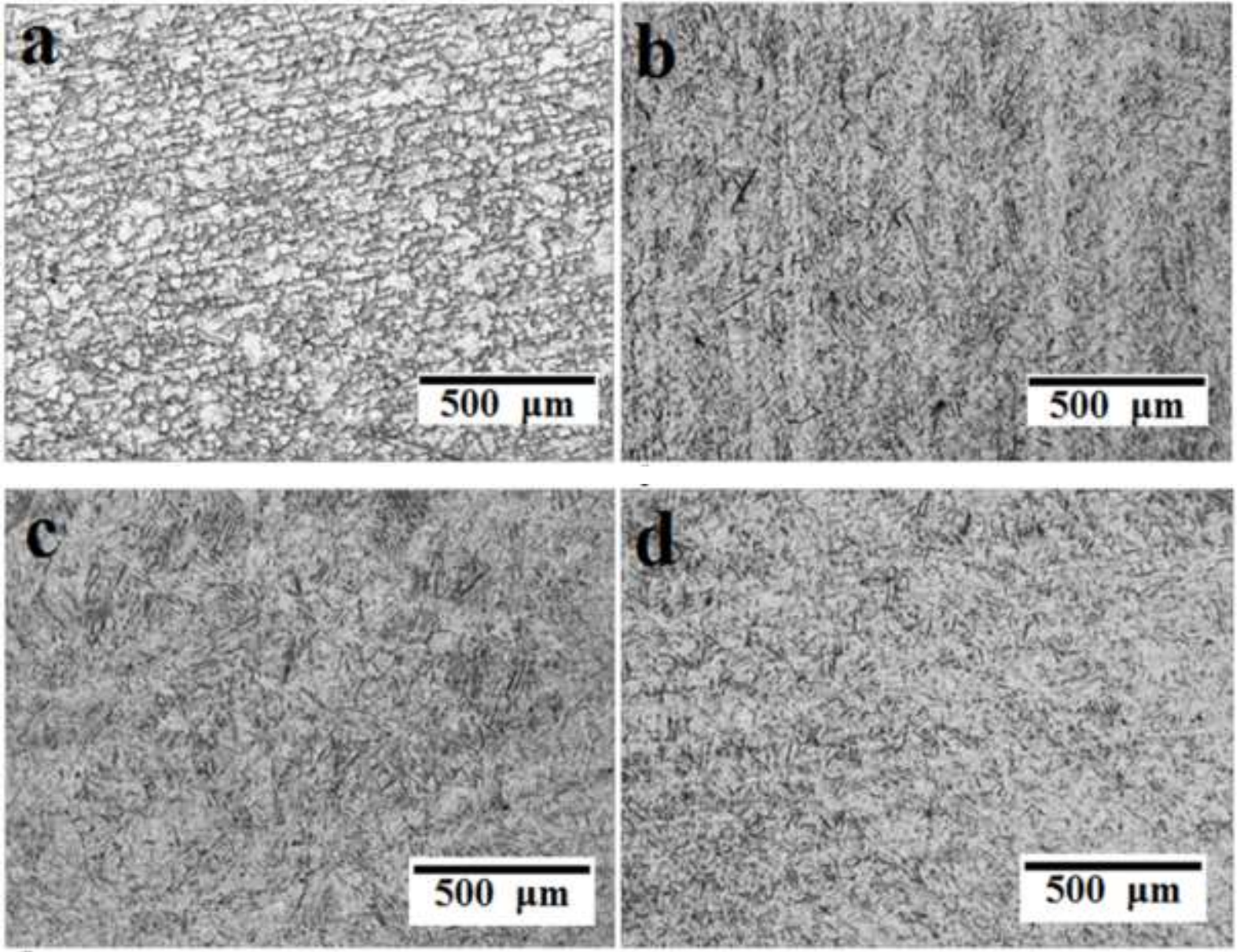

Şekil 3. Isıl işlem uygulanmış numunelerin mikroyapıları a) Fırın b) Yağ c) Su d) Isıl İşlemsiz

Bu mikroyapıların tamamı aynı büyütme oranlarında alınmıştır. Ancak her optik resim farklı 1sıl işlem uygulanmış numuneye aittir. Şekil 3'd resmi isıl işlemsiz numuneye aittir. Bu resimde asiküler martenzit içeren yapılar mevcuttur [21]. Isıl işlemsiz numunede yapı oldukça homojen görünümdedir. Tane boyutları ve yapıları haddeleme yönüne göre değişmemektedir. Yapı içerisinde martenzit ve östenit yapılar mevcuttur.

Isıl işlem genel olarak çelik malzemede istenilen sıcaklığa kadar çıkılması bir süre bekletilmesi ve sonra tekrar (farklı ortamlar) soğutulması esasına dayanır. Bu farklı soğutma ortamları sayesinde aynı çelik malzemeden farklı yapısal fiziksel ve mekanik özellikler elde etmek mümkün olmaktadır. Ötektoid altı çeliklerde 1 sıl işlemler yapılırken $\mathrm{Ac}_{3}$ sıcaklığının üzerine çıkmak gereklidir. Çünkü haddeden çıkan ürünlerde oluşan martenzit yapıları dağıtmak için östenit fazına çıkmak gerekir. Dolayısıyla Ramor 500 çeliğinin içeriğinin \% $0.3 \mathrm{C}$ ihtiva ettiğininde bildiğimize göre 1 sıl işlemlerin $900{ }^{\circ} \mathrm{C}$ civarında oluşu $\mathrm{Ac}_{3}$ çizgisini geçmek için yeterlidir. Ancak soğutma ortamları oluşacak yeni mikroyapıların durumuna göre farklı sertlik ve mekanik özellikler göstermesine neden olur. Şekil 3'a 1sıl işlem uygulanmış ancak firın içerisinde soğutulmuş numuneye aittir. Isıl işlem için östenit fazına çıkmış numune firın ortamında soğutulurken kısmen martenzit oluştururken östenit yapısınıda korumaya devam etmektedir. Östenit 
yapı "a" içerisinde homojen olarak dağılmıştır. "a" resmi dikkatli incelendiğinde östenit yapılar hadde yönünde birbirine paralel uzanmıştır. Şekil 3'b de 1sıl işlem uygulanmış yağ ortamında soğutulmuş numuneye aittir. Yapıya bakıldığında birbirine paralel bantlaşmış tanelerin görüldüğü, açık atmosferdeki soğutmaya göre daha ince taneler oluşmuştur. Şekil 3'c de 1sıl işlem uygulanmış suda soğutulmuş numuneye ait olup, yapıdaki taneler tamamen martenzitik yapıya ulaştı̆̆ından firın, ve yağ' daki soğutma işlemindeki yapılardan daha ince taneli yapıya ulaşmıştır.

\subsection{Mikrosertliğin İncelenmesi}

Numunelerin $0.5 \mathrm{HV}$ yükünde $0.5 \mathrm{~mm}$ aralıklarla 5 ayrı noktadan sertlikleri alınıp ortalama değerleri Şekil 4'de gösterilmiştir.

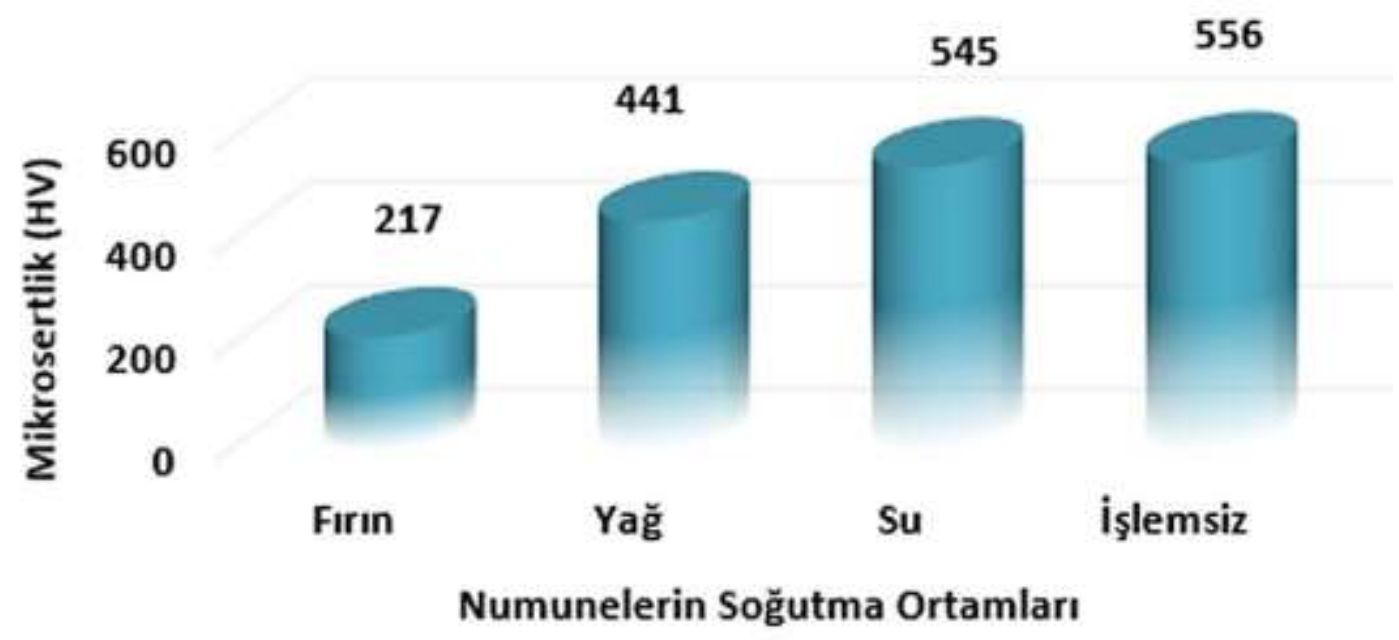

Şekil 4. Isıl işlem uygulanmış numunelerin mikro sertlik işlemleri

Isıl işlem sonrası suya çekilmiş numunenin soğuma hızı yağda soğutma işlemine göre 3 kat daha hızlıdır. Bu sebeple suda soğutma yağda soğutmadan daha fazla sertlik değeri Şekil 4'de görüldügü gibi ortaya çıkmıştır. En düşük soğuma hızı ise firın ortamında gerçekleştiğinden en düşük sertlik değeri firın ortamında oluşmuştur. Bu sebeple yüksek hızlı soğutma, malzemenin sertliğinde görüldüğü gibi önem arz etmektedir. Sertlik analizleri sonucunda, 1 s1l işlem görmüş numunelerin 1 sil işlem görmemiş ana numuneden düşük çıkmasının nedeni, Ramor 500 zırh çeliğinin üretici firma tarafından yapılan farklı özel 1 sıl işlemlerinin olduğudur.

\subsection{Abrasiv Așınma Sonuçlarının Taguchi Metoduyla İncelenmesi}

Tablo 3'deki parametreler ve seviyesine göre yapılan abrasiv aşınma işlemleri karışık orthogonal $\mathrm{L}_{16}(4 * 2,2 * 2)$ dizinine göre yapılmıştır. Tablo 4'de abrasiv aşınma deneyleri sonucunda elde edilen aşınma kütle kayıpları ve $\mathrm{S} / \mathrm{N}$ oranları verilmektedir. Tablo 5 'de abrasiv aşınma işlemi sonunda elde edilen en küçük en iyi (the smallest, the best), ilkesiyle çalışan sisteme göre, faktör seviyelerine göre $\mathrm{S} / \mathrm{N}$ oranları verilmektedir. İșlemde $\mathrm{S} / \mathrm{N}$ oranlarının ortalamas1 $-35,4307 \mathrm{~dB}$ olarak hesaplanmıştır. 
Tablo 4. Numunelerin deneysel kütle kaybı oranı ve S/N oranının hesaplanması

\begin{tabular}{|c|c|c|c|c|c|c|}
\hline \multirow{2}{*}{$\begin{array}{l}\text { Sira } \\
\text { No }\end{array}$} & \multicolumn{4}{|c|}{ Kontrol Faktörleri } & \multirow{2}{*}{$\begin{array}{c}\text { Ölçülen Kütle } \\
\text { Kaybı (gr) }\end{array}$} & \multirow{2}{*}{ S/N Oranı } \\
\hline & $\mathbf{A}$ & $\mathbf{B}$ & $\mathbf{C}$ & D & & \\
\hline 1 & Firın & 10 & 6 & 120 & 0,0189 & $-40,72424345$ \\
\hline 2 & Firın & 20 & 6 & 120 & 0,0307 & $-40,17547849$ \\
\hline 3 & Firın & 30 & 16 & 180 & 0,0808 & $-27,01330283$ \\
\hline 4 & Firın & 40 & 16 & 180 & 0,0888 & $-24,42251056$ \\
\hline 5 & Yağ & 10 & 6 & 180 & 0,0235 & $-41,83029962$ \\
\hline 6 & Yağ & 20 & 6 & 180 & 0,0302 & $-38,06179974$ \\
\hline 7 & Yağ & 30 & 16 & 120 & 0,0621 & $-31,83520069$ \\
\hline 8 & Yăg & 40 & 16 & 120 & 0,0881 & $-30,78204314$ \\
\hline 9 & $\mathrm{Su}$ & 10 & 16 & 120 & 0,0421 & $-38,93843113$ \\
\hline 10 & $\mathrm{Su}$ & 20 & 16 & 120 & 0,0784 & $-31,83520069$ \\
\hline 11 & $\mathrm{Su}$ & 30 & 6 & 180 & 0,0218 & $-36,02685826$ \\
\hline 12 & $\mathrm{Su}$ & 40 & 6 & 180 & 0,0393 & $-34,47076392$ \\
\hline 13 & $\begin{array}{c}\text { Isıl } \\
\text { İşlemsiz }\end{array}$ & 10 & 16 & 180 & 0,0355 & $-35,54567058$ \\
\hline 14 & $\begin{array}{c}\text { Isıl } \\
\text { İşlemsiz }\end{array}$ & 20 & 16 & 180 & 0,0568 & $-34,51684301$ \\
\hline 15 & $\begin{array}{c}\text { Isıl } \\
\text { İşlemsiz }\end{array}$ & 30 & 6 & 120 & 0,0315 & $-40,17547849$ \\
\hline 16 & $\begin{array}{c}\text { Isıl } \\
\text { İşlemsiz }\end{array}$ & 40 & 6 & 120 & 0,0389 & $-40,53744293$ \\
\hline
\end{tabular}

Tablo 5. Numunelerin ve seviyelerinin $\mathrm{S} / \mathrm{N}$ tablosu

\begin{tabular}{ccccc}
\hline & \multicolumn{4}{c}{ S/N oranı } \\
\cline { 2 - 5 } Parametreler & Seviye I & Seviye II & Seviye III & Seviye IV \\
\hline A & 26,90 & 27,05 & 27,74 & 28,04 \\
\hline B & 30,89 & 26,92 & 27,31 & 24,61 \\
\hline C & 23,96 & 30,91 & & \\
\hline D & 27,23 & 27,64 & & \\
\hline
\end{tabular}

Tablo 4 ve Tablo 5'de kontrol faktörü olarak seçilen verilerin, abrasiv aşınma direnci sonucu elde edilen kütle kayıpları hesaplanarak $\mathrm{S} / \mathrm{N}$ oranları tablosu yapılmıştır. Her kontrol faktörü için $\mathrm{S} / \mathrm{N}$ oranında en büyük değere sahip olan seviye, o faktör için en iyi seviye anlamına gelmektedir. Tablo 5 bu şekilde oluşturulmuştur [5-7]. Dolayısıyla A1B2C1D1 denklemi optimum şartların sağlandığ1 değerlerdir. S/N oranın sonucu büyük çıktığı seviye tüm faktörlerin seviyeleri karşılaştırılırsa o seviye en optimum seviyeyi vermektedir. Şekil 5'de çalışmanın S/N oranlarının, kontrol faktörleri ve seviyeleri arasındaki ilişki gösterilmektedir. Şekil 6' da ise mikro alaşımlı Ramor 500 çeliğinin Taguchi dizaynına göre aşındırıldıktan sonra, bu numunelerin faktör ve seviyelerin abrasiv aşınma direncinde kütle kaybına etkileri görülmektedir. 


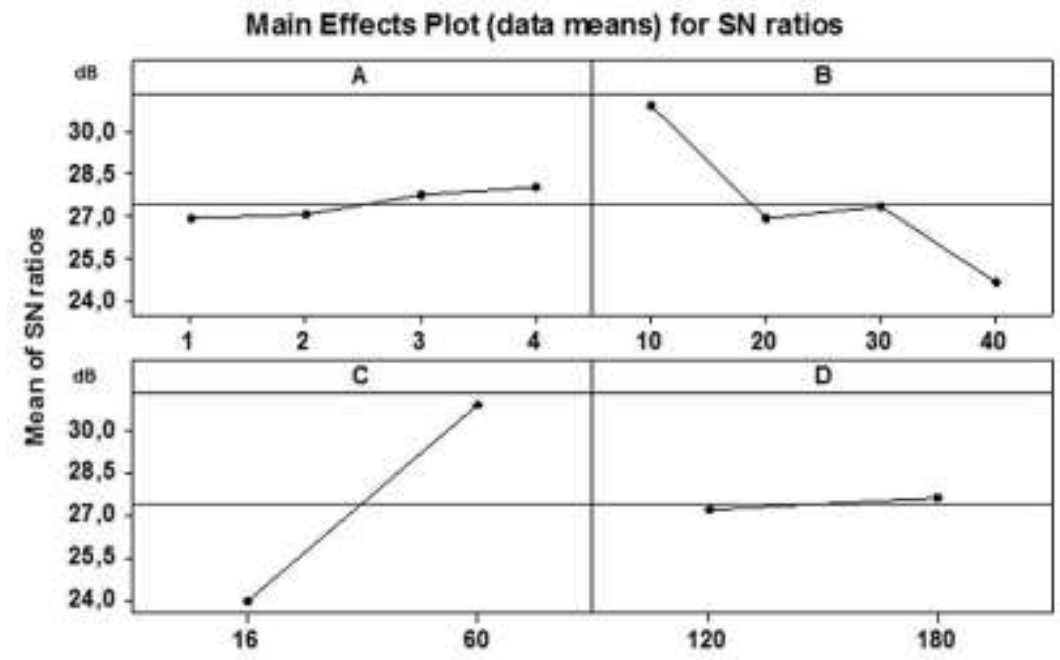

Signal-to-noise: Smaller is better

Şekil 5. Numunelerin $\mathrm{S} / \mathrm{N}$ oranları etki grafiği $(\mathrm{dB})$

Main Effects Plot (data means) for Means

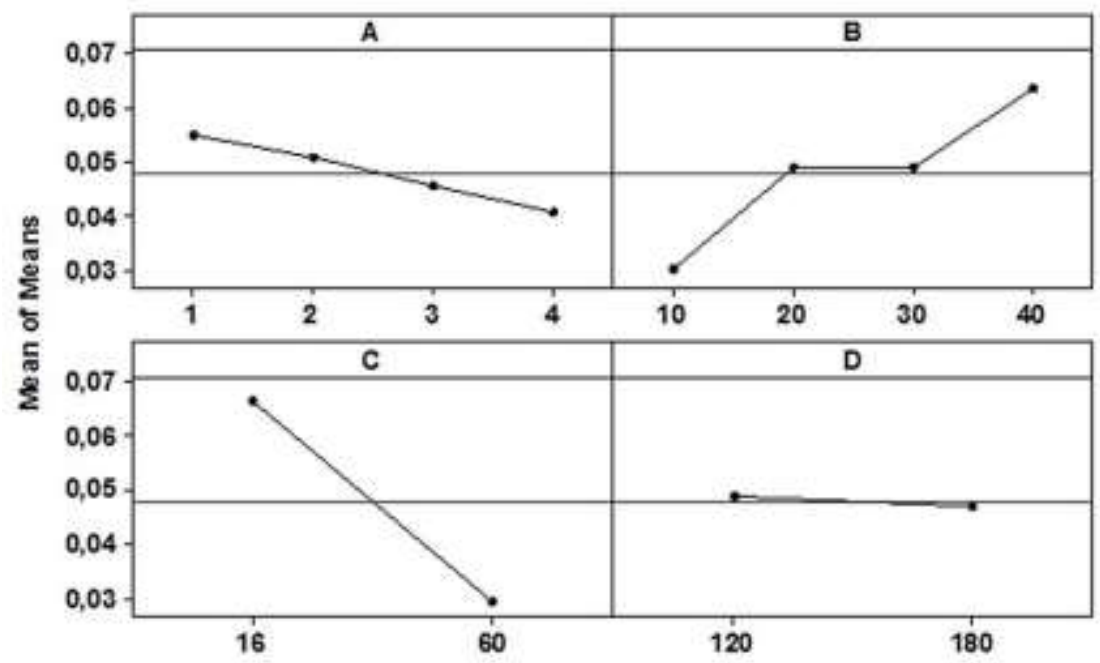

Şekil 6. Numunelerin gerçek kütle kaybı oranları etki grafiği (gr)

Şekil 7'de kütle kaybının kontrol faktörleri üzerindeki etkisi countour plot renk dağılımı metoduyla verilmiştir. Bu grafiklerde kaplama tabakasının diğer her bir kontrol faktörünün kütle kaybına olan etkisi harita olarak verilmiştir.

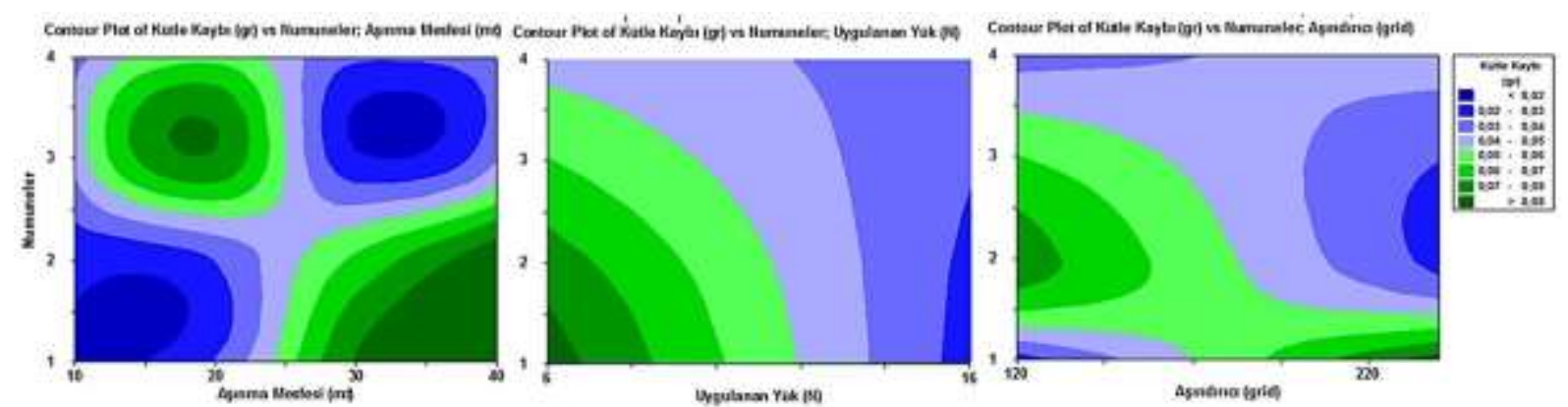

Şekil 7. Numunelerin kütle kaybının Contour Plot renk grafiği 
Abrasiv aşınma davranışının yapılan varyans analizleri sonuçlarında faktörlerin aşınma direnci üzerindeki etkileri sayısal olarak hesaplanmıştır. Varyans analizi sonuçları Tablo 6'da verilmiştir.

Tablo 6. Numunelerin kütle kaybı Varyans analizi sonuçları

\begin{tabular}{cccccc}
\hline Sembol & Df & Ss & Variance & F & $\mathbf{p}^{\mathbf{a}}(\mathbf{\%})$ \\
\hline Numuneler & 3 & 42,72337 & 14,24112 & 6,232047 & 8,946156 \\
\hline Așınma Mesafesi (m) & 3 & 104,947 & 34,98234 & $15,3086^{\mathrm{b}}$ & 24,46594 \\
\hline Uygulanan Yük (N) & 1 & 203,8696 & 203,8696 & $89,21521^{\mathrm{b}}$ & 50,27905 \\
\hline Aşındırcı Tane Boyutu (mesh) & 1 & 33,39531 & 33,39531 & $14,6141^{\mathrm{b}}$ & 7,759476 \\
\hline Hata & 7 & 15,99601 & 2,285144 & 0 & 8,549384 \\
\hline TOPLAM & & 400,9313 & & & \\
\hline
\end{tabular}

Df ; Serbestlik derecesi; ss; Kareler Toplamı; a Katkı Oranı, b 99 \% Güven seviyesi

Ayrıca kontrol faktörlerinin aşınma direncine yüzde olarak etkileri ve hata yüzdesi grafiksel olarak Şekil 8'de gösterilmiştir. Grafik incelendiğinde bütün faktörlerin sonuç üzerinde etkili olduğu görülmektedir. Grafikte de görüldüğü gibi uygulanan yük \%50 oranıyla en büyük etkiye sahiptir.

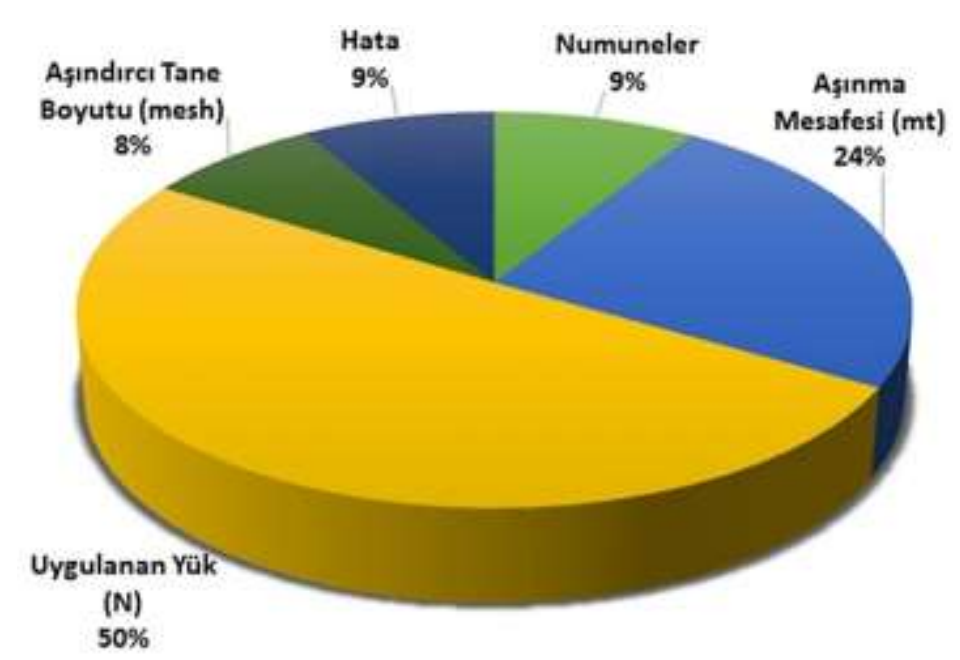

Şekil 8. Numunelerin kontrol faktörlerinin aşınma direncine \% etkisi

$\mathrm{S} / \mathrm{N}$ oranı grafikleri incelendiğinde en optimum seviyelerin A4B1C1D2 olduğu görülmektedir. Bu seviyelerdeki optimum S/N oranının elde edilmesinde 1 nolu denklem kullanılmıştır.

$$
\eta_{\text {opt }}=\eta_{m}+\sum_{i=1}^{j}\left(\eta_{i-} \eta_{m}\right)
$$

$\eta_{\text {opt }}$, optimum $\mathrm{S} / \mathrm{N}$ oranın1, $\eta_{\mathrm{m}}$, ortalama $\mathrm{S} / \mathrm{N}$ oranlarının ortalamas1, $\eta_{\mathrm{i}}$ her bir parametrenin ideal olan seviyesinin S/N oranını göstermektedir. Yapılan hesaplamada optimum S/N oranı 16. satırda 25,19206145 dB bulunmuştur. Bu denklemden elde edilen optimum $\mathrm{S} / \mathrm{N}$ oranı en küçük en iyi (the smallest, the best), kalite karakteristiğine göre optimum ortalama aşınma miktarının hesaplanması sağlanmıştır.

$$
\text { Wear }_{\text {opt }}=\sqrt{10^{-\frac{\eta_{\text {opt }}}{10}}}
$$

2.nolu denklemde $\mathrm{Wear}_{\text {opt, }}$ optimum ortalama aşınma miktarını ifade etmektedir. Optimum ortalama aşınma miktarı 16. satırda 0,055004336 gr olarak hesaplanmıştır. 


\section{Sonuçlar}

Aşınma, yüzeyler birbirine temas ettiğinde ortaya çıkar. Temas yüzeyinden aşınma kaybı getirir. Az mukavemet, aşınma direncinde az dayanıklılığa sebebiyet verir. Yüke dayanmak, sertliğini arttırmak, korozyon direnci sağlamak için uygun alaşımlı malzeme seçimi esas temeldir. Bu çalışma sonucunda;

- Yapılan $1 s 1$ işlemler sonrasında sertlik değerlerinde esas metalin altında kalınmıştır. Çünkü Ramor 500 serisi çeliklerde üretimde kullanılan soğutma sistemleri ticari sır olarak saklanıyor.

- Seçilen bütün parametrelerin aşınmaya etkisi olmuştur.

- Kütle kaybının kontrol faktörleri üzerindeki etkisi contour plot renk dağılımı metoduyla gözlemlenmiştir.

- Yapılan Varyans analizine göre aşınmaya en yüksek etkiyi uygulanan yükler, en düşük etkiyi ise numuneler yapmiştır.

- S/N grafikleri incelendiğinde en optimum seviyelerin A1B2C1D1 olduğu görülmüştür.

- Optimum aşınma oranı 16. satırda 0,055004336 gr olarak hesaplanmıştır.

Sonuç olarak; 1sıl işlem Hardox 400 çeliğin aşınma özelliklerine çok etki etmemiştir. Çünkü Varyans analizinde numunelerin \% 9 gibi çok küçük etkiye sahip olduğu görülmektedir. Ancak bu durumda da olsa sonuçlar göz ardı edilmeyecek olan sertlik değerlerinde belirgin düşüş̧e sebep olmaktadır. Bu durum en çok kaynaklı birleştirmelerde ITAB oluşan mikroyapısal değişimlerde kaynaklı birleştirmelerin mukavemet özelliklerinde sıkıntıya sebep olabilir.

\section{Teşekkür}

$\mathrm{Bu}$ çalışma Fırat Üniversitesi Bilimsel Araştırma Projeleri (FÜBAP) birimi tarafından TEKF. 16.24 numaralı proje kapsamında desteklenmiştir.

\section{Kaynaklar}

[1] Memiş İ. 2016. Impact Response Of Ramor 500 Armor Impact Response Of Ramor 500 Armor Steel Subjected To High Velocities. Graduate School of Natural and Applied Science of Dokuz Eylül University In Partial Fullfilment of the Requirements for the Master of Science of Mechanical Engineering, Mechanic Program, İzmir.

[2] Karagöz Ş., Atapek Ş.H., Yılmaz A. 2008. Zırh çeliklerinde perforasyon ve balistik korumanın anlaşılması açısından fragtografik etüd. Metal Dünyası, 182: 102-107.

[3] Taskaya S., Gur A.K., Orhan A. 2019. Joining of Ramor 500 Steel by Submerged Welding and its Examination of Thermal Analysis in Ansys Package Program. Thermal Science and Engineering Progress, 11: 84-110.

[4] Lane R., Craig B., Babcock W. 2002. Materials for Blastand Penetration Resistance, The Amptrac Quartely, 6 (4): 39-45.

[5] Sangoy L., Meunier Y., Pont G. 1988. Steelsfor Ballistic Protection. Israel Journal of Technology, 24: 319-326.

[6] Ade F. 1991. Ballistic Qualification of Armor Steel Weldments. Welding Journal, 70: 53-58.

[7] Jacobi H., Batinmann H.J., Gronsfeld J. 1988. New Method of Determining the Macrocleanness of Unconventionally Rolled Continuously Cast Steel. StahlEisen, 108 (20): 54-66.

[8] Taguchi G. 1988. Introduction To Taguchı Methods., Eng., 228 (1).

[9] Savas V., Ozay C., Ballikaya H. 2016. Experimental investigation of cutting parameters in machining of 100Cr6 with tangential turn-milling method. Adv. Manuf., 4 (1): 97-104.

[10] Ross P.J. 1998. Taguchi Techniques for Quality Engineering, Loss Fuction, Orthogonal Exp. Param. Toler. Des., p: 279, McGraw-Hill, New York.

[11] Gür A.K., Yildiz T., Kati N., Kaya S. 2019. Microstructure and wear of FeCrC, SiC and B4C coated AISI 430 stainless steel. Materials Testing, 61 (2): 173-178.

[12] Ozay C. 2014. Investigating the Surface Roughness after Tangential Cylindrical Grinding by the Taguchi Method. Materials Testing, 56 (4): 306-311.

[13] Yildiz T., Gür A.K., Aba S. 2014. Examination of the Wear Behavior of Cu-Ni/B4Cp Composite by the Taguchi Method. Materials Testing, 56 (11-12): 1009-1014. 
[14] Gajjal S.Y., Unkule A.J., Gajjal, P.S. 2018. Taguchi technique for dry sliding wear behavior of PEEK composite materials. Materials Today: Proceedings, 5 (1): 950-957.

[15] Paturkar A., Mache A., Deshpande A., Kulkarni A. 2018. Experimental investigation of dry sliding wear behaviour of jute/epoxy and jute/glass/epoxy hybrids using Taguchi approach. Materials Today: Proceedings, 5 (11): 23974-23983.

[16] Hofinger M., Staudacher M., Ognianov M., Turk C., Leitne H., Schnitzer R. 2019. Microstructural evolution of a dual hardening steel during heat treatment. Micron, 120: 48-46.

[17] Atapek Ş.H. 2011. Bor katkılı bir zırh çeliğginin fiziksel metalurjik esaslar doğrultusunda geliştirilmesi ve balistik performansının değerlendirilmesi. Doktora Tezi, Kocaeli Üniversitesi Fen Bilimleri Enstitüsü, Kocaeli.

[18] Atapek Ş.H. 2006. Zırh Çeliklerinin Fiziksel Metalurjik Esaslar Doğrultusunda Geliştirilmesi ve Karakterizasyonu. Yüksek Lisans Tezi, Kocaeli Üniversitesi Fen Bilimleri Enstitüsü, İzmit.

[19] Karakoç H., Ulutaş A., Çinici H. 2019. B4C/SiC/A12O3 Parçacık Takviyelendirilmiş Alüminyum Sandviç Köpük ile Ramor 500 Zırh Çeliğinin bir araya getirilmesi ve Balistik Performansının Araştırılması. Politeknik Dergisi, 22 (3).

[20] Cengiz M.H. 2018. Hardox 400 Çelik Yüzeyinin Plazma Transferli Ark Kaynak Yöntemiyle Alaşımlandırılması ve Taguchi Metoduyla Değerlendirilmesi. Yüksek Lisans Tezi, Fırat Üniversitesi Fen Bilimleri Enstitüsü, Elazı̆̆.

[21] Balakrishnan M., Balasubramanian V., Madhusudhan Reddy G. 2013. Microstructural Analysis Ballistic Tests on Welded Armor Steel Joints. Metallogr. Microstruct. Anal., 2: 125-139.

[22] Taşkaya S., Gür A. 2019. Ramor 500 Zırh Çeliğinin Tozaltı Kaynak Yöntemi İle Birleştirilmesinde Tel İlerleme Hızının Kaynak Metalindeki Nüfuziyet Dengesinin İncelenmesi. Gümüşhane Üniversitesi Fen Bilimleri Enstitüsü Dergisi, 9 (2).

[23] Taşkaya S., Yıldız T., Gür A. 2018. The Effect of Voltage on Joining of Ramor 500 Armor Steel With Submerged Arc Welding Method. Sakarya University Journal of Science, 22 (2): 357-363. 